\title{
Utilização de auxiliares odontológicos em Ortodontia - implicações éticas e legais
}

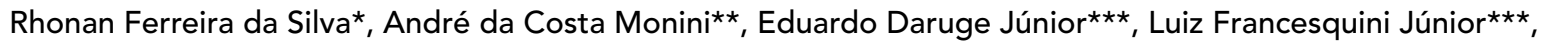

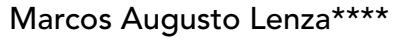

\section{Resumo}

Introdução: o mercado de trabalho tem se mostrado saturado de profissionais atuando nos grandes centros urbanos e, por este motivo, as estratégias de produtividade são imprescindíveis. A delegação de funções aos auxiliares odontológicos tem se tornado vital e corriqueira para aqueles que exercem a Ortodontia. Objetivo: conhecer o perfil do cirurgião-dentista especialista nesta área e as funções delegadas por ele à equipe auxiliar. Metodologia: foi aplicado um questionário a todos os especialistas em Ortodontia e Ortopedia Facial inscritos no Conselho Regional de Odontologia de Goiás, com atividade em Goiânia e Aparecida de Goiânia. Resultados e Conclusões: os resultados demonstraram que os ortodontistas, de um modo geral, aproveitam bem a mão-de-obra auxiliar chegando até a ultrapassar os limites ético-legais.

Palavras-chave: Ortodontia. Auxiliares de Odontologia. Odontologia legal. Ética.

\section{INTRODUÇÃO}

Atualmente, o tratamento ortodôntico corretivo vem sendo parcialmente desmistificado, devido ao surgimento de novos conhecimentos aliado ao desenvolvimento de novas técnicas, materiais e procedimentos, tornando-o mais acessível para que uma maior quantidade de profissionais o execute. Neste ínterim, a grande oferta de cursos de pós-graduação contribuiu para que a Ortodontia se encontrasse inserida num contexto competitivo, tendo seu acesso facilitado pela considerável oferta de mão-de-obra que disputa o mercado.

A popularização da Ortodontia fez com que os profissionais que atuam nesta área adquirissem mé- todos que agilizassem o atendimento dos pacientes, com o intuito de aumentar a produtividade e diminuir custos. Dentre os diversos métodos, destacam-se a adaptação do local de trabalho para o atendimento simultâneo de pacientes e a delegação da maior quantidade possivel de funções à equipe auxiliar.

De um modo geral, a utilização de pessoal auxiliar no consultório odontológico torna-se fundamental para se conseguir um aumento na produtividade, estando também relacionada com a melhoria da qualidade de trabalho, diminuição do estresse e fadiga profissional além da possibilidade de execução dos procedimentos com maior ergonomia e diminuição do custo

* Mestre em Odontologia Legal FOP/UNICAMP. Professor de Odontologia Legal UNIP (GO).

** Especializando em Ortodontia FOAr/UNESP.

*** Professor Doutor em Odontologia Legal FOP/UNICAMP.

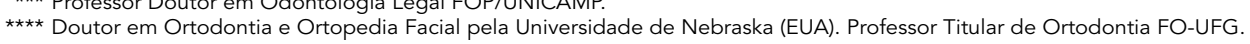


operacional $1^{8,10,11,13,17,21}$.

Primordialmente, a participação dos auxiliares odontológicos estava relacionada com o atendimento público visando minimizar um problema social de acesso aos serviços odontológicos ${ }^{15}$, mas hoje estes profissionais são utilizados para otimizar o atendimento clínico nos consultórios de um modo geral. Inserida neste contexto, a equipe auxiliar odontológica assume um papel fundamental para a agilização do tratamento odontológico. Das diversas categorias de profissionais auxiliares, as que têm uma relação mais estreita com a Ortodontia são a secretária, o Técnico em Higiene Dental (THD) e o Atendente de Consultório Dentário (ACD). No consultório odontológico, secretária é a função exercida por quem auxilia o profissional da Odontologia em questões administrativas (recepção, agenda de pacientes, correspondências, dentre outras funções) e que não possui curso de formação ou habilitação legal para exercer as atribuições de ACD ou THD. Recentemente, o ACD teve a sua nomenclatura modificada para Auxiliar de Consultório Dentário, por meio da Decisão $n^{\circ} 47$ editada pelo Conselho Federal de Odontologia ${ }^{4}$.

As categorias de THD e ACD tiveram os seus currículos mínimos de formação estabelecidos por meio do Parecer $n^{\circ} 460 / 75$ do Ministério da Educação, mas a área de atuação bem como as atribuições específicas de cada função estão atualmente regulamentadas pelo Conselho Federal de Odontologia (CFO), por meio da Resolução CFO 063/2005 ${ }^{3}$. Esta resolução revogou a antiga Consolidação das Normas para Procedimentos nos Conselhos de Odontologia, editada pela Resolução CFO n 185/93, mas conservou boa parte do seu conteúdo, inclusive aquele relacionado com as atribuições específicas da equipe auxiliar odontológica. Recentemente, o Ministério da Saúde publicou um manual ${ }^{2}$, sustentado pelo Código de Ética Odontológica $^{5}$ e na antiga Resolução CFO 185/93, contendo o perfil de competências profissionais do THD e do ACD com o intuito de fornecer subsídios às instituições formadoras. A observação destas nor- mas propicia ao cirurgião-dentista a possibilidade de delegar diversas funções à equipe auxiliar sem, contudo, ferir os princípios éticos e legais que regem o exercício da Odontologia.

Tendo em vista a importância da utilização de pessoal auxiliar na prática odontológica, torna-se apropriado analisar se o especialista em Ortodontia e Ortopedia Facial tem conhecimento das funções que podem ser delegadas a esta equipe (THD, ACD e secretária), correlacionando com as atribuições permitidas e estabelecidas na legislação vigente, bem como analisar o perfil dos profissionais que exercem esta especialidade.

\section{MATERIAL E MÉTODO}

Para a realização do presente estudo elaborou-se um questionário contendo questões estruturadas, as quais sinalizam aspectos inerentes à formação profissional do especialista em Ortodontia e Ortopedia Facial, devidamente inscrito no Conselho Regional de Odontologia de Goiás (CRO-GO), à atualização de seus conhecimentos e à delegação de funções à equipe auxiliar. Algumas questões eram compostas por múltiplas alternativas, podendo os ortodontistas assinalarem mais de uma. Nestes questionários foi assegurada, a cada participante, a confidencialidade das informações prestadas, além do uso exclusivo para fins de pesquisa, por meio de um Termo de Consentimento Livre e Esclarecido, sendo que os mesmos, em número de 95 , foram aplicados nos municípios de Goiânia e Aparecida de Goiânia, ambos no Estado de Goiás. A presente pesquisa foi devidamente aprovada pelo Comitê de Ética em Pesquisa da Faculdade de Odontologia de Piracicaba - UNICAMP, sob o número 137/2003. Os dados obtidos nos questionários foram informatizados e, para tal, foi confeccionado um banco de dados, utilizandose planilhas do Microsoft Excel 2000. O mesmo programa foi utilizado para o levantamento das freqüências das respostas e os resultados foram analisados por estatística descritiva. 


\section{RESULTADOS}

Dos 95 questionários aplicados, 84 (88,4\%) foram devolvidos e apresentavam-se devidamente respondidos. Dentre o total de questionários válidos (84), observou-se que $61,9 \%$ da amostra eram compostos por profissionais do gênero masculino e o restante $(38,1 \%)$ era do gênero feminino.

Quando analisado o perfil de formação dos profissionais entrevistados, constatou-se que $60,7 \%$ se graduou em faculdades de Odontologia públicas e os demais $(39,3 \%)$ em instituições particulares. Em relação à formação de pós-graduação em Ortodontia e Ortopedia Facial, 83,3\% dos entrevistados possuía especialização nestas áreas, 21,4\% possuía mestrado e 2,4\% doutorado.

Em relação à freqüência de atualização dos conhecimentos em Ortodontia, 31\% buscam cursos relacionados a esta área trimestralmente, $21,4 \%$ semestralmente, $13,1 \%$ anualmente e os demais em outra periodicidade.

Analisando o tempo de exercício profissional como especialista em Ortodontia e Ortopedia Facial, constatou-se que 30,9\% atuavam em um período inferior a cinco anos, $32,1 \%$ entre cinco e dez anos, $27,4 \%$ entre dez e vinte anos e 9,6\% em um período superior a vinte anos.

Com relação ao local de trabalho, todos os entrevistados atuavam em clínica particular, 9,5\%

Tabela 1 - Relação dos profissionais auxiliares que trabaIham junto ao ortodontista.

\begin{tabular}{ccc}
\hline categoria profissional & $\begin{array}{c}\text { número de } \\
\text { profissionais }\end{array}$ & $\%$ \\
\hline ACD & 62 & 73,8 \\
secretária & 61 & 72,6 \\
ACD e secretária & 36 & 42,8 \\
THD & 14 & 16,7 \\
ACD (exclusivamente) & 14 & 16,7 \\
secretária (exclusivamente) & 16 & 19 \\
THD, ACD e secretária & 7 & 8,3 \\
THD e ACD & 5 & 6 \\
não emprega & 4 & 4,8 \\
THD e secretária & 2 & 2,4 \\
\hline $\mathrm{n}=84$. & &
\end{tabular}

também trabalhavam em instituições de ensino superior, $4,8 \%$ em serviço público e $3,6 \%$ em clínicas de terceiros.

Em relação à obtenção de conhecimentos e orientações odonto-legais, verificou-se que $85,7 \%$ da amostra cursaram a disciplina de Odontologia Legal e/ou Ética na graduação e $60,7 \%$ na pósgraduação.

Com relação ao emprego de profissional auxiliar, constatou-se que $73,8 \%$ empregavam ACD, $72,6 \%$ secretária e 16,7\% trabalhavam com THD, conforme tabela 1.

Quando questionado ao ortodontista sobre onde está presente a legislação que estabelece quais as funções que podem ser delegadas à equipe auxiliar, 53,6\% não sabiam, 25\% citaram a resolução CFO 185/93 (que corresponde atualmente à Resolução CFO 063/2005³) e 21,4\% citaram o Código de Ética Odontológica (CEO) ${ }^{5}$.

Quando questionado ao ortodontista se os profissionais da sua equipe auxiliar trabalhavam diretamente com o paciente, $38 \%$ relataram que não e o restante (62\%) respondeu que sim ou eventualmente.

Do total de ortodontistas, $67,8 \%$ relataram que estão presentes fisicamente quando os profissionais

Tabela 2 - Funções estabelecidas na Resolução CFO 063/2005 ${ }^{3}$ que podem ser delegadas pelos ortodontistas aos THD.

\begin{tabular}{|c|c|c|}
\hline \multirow{2}{*}{ funções delegadas pelo ortodontista } & \multicolumn{2}{|c|}{ freqüência } \\
\hline & absoluta & relativa $(\%)$ \\
\hline realizar teste de vitalidade pulpar & 0 & 0 \\
\hline $\begin{array}{l}\text { realizar a remoção de indutos, placas e } \\
\text { cálculos supragengivais }\end{array}$ & 8 & 9,5 \\
\hline responder pela administração da clínica & 13 & 15,5 \\
\hline $\begin{array}{l}\text { fazer a tomada e revelar radiografias } \\
\text { intrabucais }\end{array}$ & 21 & 25 \\
\hline $\begin{array}{l}\text { participar do treinamento de Auxiliar de } \\
\text { Consultório Dentário (ACD) }\end{array}$ & 49 & 58,3 \\
\hline confeccionar modelos & 65 & 77,4 \\
\hline $\begin{array}{l}\text { fazer a demonstração de técnica de } \\
\text { escovação }\end{array}$ & 69 & 82,1 \\
\hline preparar moldeiras & 73 & 87 \\
\hline
\end{tabular}


da equipe auxiliar estão trabalhando diretamente com o paciente, $26,2 \%$ não e $6 \%$ estão presentes eventualmente.

Dentre as diversas funções delegadas pelo ortodontista à equipe auxiliar odontológica, as presentes na tabela 2 estão enumeradas como atribuições legalmente permitidas para o THD e na tabela 3 as permitidas para o ACD realizarem junto ao ci- rurgião-dentista. Na tabela 4 foram relacionados outros procedimentos, comuns da rotina de tratamento ortodôntico, e que não estão relacionados na Resolução CFO 063/2005³.

\section{DISCUSSÃO}

Nos tempos atuais, a Odontologia presencia um momento em que o mercado de trabalho apresen-

Tabela 3 - Funções estabelecidas na Resolução CFO 063/2005³ que podem ser delegadas pelos ortodontistas ao ACD.

\begin{tabular}{ccc}
\hline funções delegadas pelo ortodontista & \multicolumn{2}{c}{ frequiência } \\
\cline { 2 - 3 } revelar e montar radiografias intrabucais & absoluta & relativa (\%) \\
\hline selecionar moldeiras & 24 & 28,6 \\
controlar o movimento financeiro & 46 & 54,8 \\
preencher e marcar fichas clínicas & 46 & 54,8 \\
confeccionar modelos de gesso & 50 & 59,5 \\
orientar o paciente sobre higiene bucal & 51 & 60,7 \\
manipular materiais de uso odontológico & 65 & 77,4 \\
auxiliar no atendimento ao paciente & 69 & 82,1 \\
preparar o paciente para o atendimento & 72 & 85,7 \\
instrumentar o cirurgião-dentista e o THD junto à cadeira operatória & 74 & 88,1 \\
tológico & 75 & 89,3 \\
manter em ordem arquivo e fichário & 76 & 90,5 \\
marcar consultas & 77 & 91,7 \\
\hline
\end{tabular}

$\mathrm{n}=84$.

Tabela 4 - Funções não estabelecidas na Resolução CFO 063/2005³ delegadas pelos ortodontistas à equipe auxiliar.

\begin{tabular}{ccc}
\hline funções delegadas pelo ortodontista & freqüência & relativa (\%) \\
\cline { 2 - 3 } $\begin{array}{c}\text { ativação de grampos e/ou molas de aparelhos ortodônticos } \\
\text { remoção da resina que fica aderida nos dentes após a retirada do } \\
\text { aparelho ortodôntico }\end{array}$ & absoluta & 0 \\
colagem direta de braquetes & 5 & 6 \\
remoção do aparelho ortodôntico & 6 & 7,1 \\
troca de fios ortodônticos & 6 & 7,1 \\
colagem da contenção fixa & 12 & 14,3 \\
adaptação (calcar) e/ou cimentar de bandas ortodônticas & 14 & 16,7 \\
retirada ou colocação de alastic/amarrilhos & 16 & 19 \\
realização de moldagens de estudo & 36 & 42,8 \\
colocação de borrachas para a separação de dentes & 39 & 46,4 \\
\hline
\end{tabular}


ta-se repleto de profissionais atuando nos grandes centros urbanos e um dos fatores que agravou esta situação foi a abertura indiscriminada de cursos de graduação e pós-graduação. Em maio de 2005, a página na internet do $\mathrm{CFO}$ continha, cadastrados em seu banco de dados, 170 cursos de graduação em Odontologia no país, sendo que $28,8 \%$ destes eram oferecidos somente no estado de São Paulo ${ }^{6}$. Além disso, a proliferação de planos de saúde, convênios, dentre outras entidades que atuam direta ou indiretamente no âmbito odontológico, acirrou a disputa de mercado entre os cirurgiões-dentistas na conquista de um maior número de pacientes.

Certos tratamentos, como a Ortodontia corretiva, estão atualmente com o acesso facilitado ao público pela grande quantidade de profissionais que os executam. No Brasil, em maio de 2005, havia 6.605 especialistas em Ortodontia e Ortopedia Facial inscritos em todos os Conselhos Regionais de Odontologia (CRO), sendo que $32,8 \%$ estavam inscritos somente no $\mathrm{CRO}-\mathrm{SP}^{6}$. Esta grande oferta de mão-de-obra especializada aumentou a concorrência profissional, pois além de disputarem os pacientes entre si, estes profissionais também concorrem com os clínicos gerais, que tiveram a facilitação do aprendizado da Ortodontia corretiva pela enorme oferta de cursos de aperfeiçoamento nesta área.

Uma das formas de se obter um aumento na produtividade é inserindo a equipe odontológica auxiliar na execução das funções que lhe são permitidas e que estão estabelecidas na legislação que norteia a profissão. O presente trabalho observou que $95 \%$ dos ortodontistas entrevistados utilizam-se desta conduta, constituindo um resultado maior que os encontrados por Eleutério e Silva Filho $^{7}$ (81\%); Serra ${ }^{17}(79,4)$; Serra, Sasso Garcia ${ }^{18}$ $(83,2 \%)$ e Saliba et al. ${ }^{14}$ (37,5\%), demonstrando que os profissionais que exercem esta especialidade estão atentos para este quesito.

No entanto, quase a metade $(45,2 \%)$ dos ortodontistas não utiliza o seu pessoal auxiliar na aplicação de métodos preventivos para controle da cárie dentária e não delega diversas outras funções que são permitidas pela legislação vigente (Tab. 2 , 3). Serra e Sasso Garcia ${ }^{18}$ observaram que a instrumentação do cirurgião-dentista era uma função delegada por $58 \%$ dos profissionais entrevistados e neste trabalho, quase $90 \%$ dos ortodontistas se beneficia desta conduta, demonstrando que estes profissionais necessitam e usufruem mais desta vantagem quando comparados com as pesquisas realizadas com clínicos gerais.

Diante da grande utilização de profissionais auxiliares na Ortodontia, surge um ponto polêmico e que necessita de uma abordagem criteriosa: quais as atribuições que podem ou devem ser delegadas à equipe auxiliar? Para as categorias reconhecidas pelo CFO (THD e ACD), esta resposta está atualmente presente na Resolução CFO 063/2005³, norma esta que relaciona quais as atribuições específicas de cada categoria. A não observação destas orientações normativas pode propiciar a instauração de processos éticos ou criminais contra o ortodontista e contra o profissional auxiliar por extrapolar os limites de sua atuação ${ }^{19}$.

$\mathrm{Na}$ prática ortodôntica, onde o especialista nesta área pode trabalhar com mais de um profissional auxiliar (Tab. 1), é imprescindivel que o mesmo tenha conhecimento das atribuições que podem ser delegadas, de acordo com a legislação vigente. Como exemplo, pode-se citar a realização de uma moldagem de estudo, necessária para a avaliação da execução do tratamento. Sabendo que na obtenção dos modelos de gesso estão envolvidas as fases de seleção das moldeiras, preparação do material e a confecção dos modelos em gesso, observou-se que estas funções eram delegadas por $54,8 \%, 87 \%$ e $77,4 \%$ dos entrevistados, respectivamente. Considerando que a moldagem propriamente dita é atividade privativa do cirurgião-dentista, constatou-se que $46,4 \%$ dos entrevistados delegava esta função à equipe auxiliar. Estes resultados demonstram que a maior parte dos ortodontistas envolve a equipe auxiliar durante o procedimento de obtenção de modelos, inclu- 
sive permitindo que estes profissionais extrapolem suas atribuições específicas, ao delegar a realização da moldagem de estudo.

Os procedimentos relacionados na tabela 4, dentre eles a realização de moldagens de estudo, colagem direta de braquetes e a colagem de contenção fixa, constituem atribuições específicas do cirurgião-dentista e, de acordo com a legislação vigente, não podem ser delegados à equipe auxiliar.

Ao considerarmos que a atribuição de uma função está baseada na reversibilidade do $\mathrm{ato}^{18}$, seria justificável delegar alguns procedimentos em Ortodontia que não estão descritos na legislação vigente, dentre eles a retirada de elásticos de separação dentária e de alastic/amarrilho. Na execução destes atos, a probabilidade de ocasionar dano ao paciente é mínima, o que não traria prejuízo ao tratamento. Entretanto, a delegação destes procedimentos e de outros que a classe odontológica julgar pertinente, como a realização de moldagem de estudo, só seria permitida após a inclusão dos mesmos numa próxima revisão da norma regulamentadora.

Por outro lado, a revisão desta norma legal deve considerar a necessidade de conhecimento técnico-científico na realização do procedimento, estando sensível aos riscos inerentes à execução do ato. Kharbanda et al. ${ }^{9}$ relataram o caso de uma garota que engoliu uma coroa metálica durante uma sessão de tratamento ortodôntico. A paciente foi monitorada radiograficamente e o objeto deglutido foi recuperado no quinto dia após o acidente, sem necessidade de intervenção cirúrgica. Milton et al. ${ }^{12}$ relataram três outros casos onde foram deglutidas partes de aparelhos ortodônticos (fios e braquetes) de pequenas dimensões e que não causaram danos aos pacientes. Entretanto, podem ocorrer acidentes decorrentes do uso de um aparelho ortodôntico onde uma intervenção cirúrgica torna-se necessária, como no caso relatado por Abdel-Kader ${ }^{1}$, onde uma barra transpalatina quebrou e foi deglutida por uma paciente de doze anos, quando esta se alimentava. Como a colocação dos fios e bandas e a colagem de braquetes constituem atos indelegáveis na prática ortodôntica, de acordo com a norma regulamentadora vigente, qualquer acidente ocorrido durante a execução destes procedimentos será de responsabilidade direta do ortodontista. Além disso, compete ao profissional a inspeção dos objetos, materiais e aparelhos que serão utilizados ou colocados na cavidade bucal do paciente, pois estes integram o tratamento estabelecido pelo cirurgião-dentista.

No presente trabalho, constatou-se que a substituição de fios ortodônticos (14,3\%), colagem de contenção fixa $(16,7 \%)$ e adaptação e/ou cimentação de bandas ortodônticas (19\%) estão sendo delegados à equipe auxiliar. Este tipo de conduta apresenta pequeno risco imediato à saúde do paciente, mas exige grande conhecimento técnicocientífico do profissional, podendo causar complicações para o tratamento, caso sejam executados inadequadamente. A remoção do aparelho ortodôntico, delegada por $7,1 \%$ da amostra, e outros procedimentos possuem um risco de dano imediato maior, podendo levar à fratura do elemento dentário ou desgaste desnecessário da superfície do esmalte durante a remoção do braquete. Desse modo, estes procedimentos devem ser executados obrigatoriamente pelo ortodontista, não podendo ser delegados à equipe auxiliar.

Cabe ressaltar que a assistência prestada pela equipe auxiliar, que pode atuar diretamente na cavidade bucal do paciente, exige a indispensável supervisão do cirurgião-dentista, além da sua presença física durante a realização do procedimento $^{3}$. Esta conduta não foi adotada por quase um terço da amostra $(32,2 \%)$, configurando uma infração passível de punição, de acordo com as normas legais vigentes.

A delegação de procedimentos a serem realizados na cavidade bucal do paciente, que não estão discriminados na resolução CFO 063/2005³, constitui infração ética com sansões administrativas e multa aplicáveis tanto ao ortodontista quanto ao profissional auxiliar inscrito no CRO, pela conivência com o exercício ilegal da Odontologia, 
conforme estabelece o artigo $9^{\circ}$, IV do Código de Ética Odontológica ${ }^{5}$. Além disso, aquele que exerce a Odontologia de modo ilegal ou extrapolando os seus limites, infringe o artigo 282 do Código Penal Brasileiro podendo ser penalizado com detenção além de possivel multa.

No que se refere à formação odonto-legal dos ortodontistas, observou-se que $85,5 \%$ tiveram acesso a estes conhecimentos ainda durante a graduação e $60,7 \%$ um reforço na pós-graduação. No entanto, apenas $25 \%$ relataram saber onde está presente a legislação que regulamenta as atribuições delegáveis à equipe auxiliar, indicando que esta informação não está completamente consolidada, mesmo com $83,3 \%$ dos ortodontistas atualizando os seus conhecimentos pelo menos uma vez ao ano. Desse modo, torna-se necessária a busca de informações sobre a legislação que envolve o exercício de suas atividades profissionais, pelo dinamismo das modificações nas normas regulamentadoras, culminando em mudanças de conduta e comportamento.

O atual estágio da Odontologia, no que diz respeito ao acesso ao tratamento e quantidade de profissionais no mercado, mostra que a delegação de funções aos auxiliares é um processo irreversível, principalmente quando relacionado ao tratamento ortodôntico. Em outros países, a atuação dos auxiliares na Ortodontia apresenta-se bem mais abrangente que no Brasil. Seeholzer et al. ${ }^{16}$ constataram, em uma pesquisa realizada em vinte e dois países da Europa, que a cimentação de bandas e a colocação/remoção de arcos eram funções delegadas aos auxiliares odontológicos em 5 e 10 países, respectivamente. $\mathrm{Na}$ Escandinávia, os auxiliares podem ajustar separadores dentários, colar braquetes, remover arcos e aparelhos fixos ${ }^{20}$.

Diante destes fatos e sabendo que diversos procedimentos realizados na prática ortodôntica, não permitidos pela legislação vigente, estão sendo delegados à equipe auxiliar; seria prudente a revisão responsável da norma que define a atuação destes profissionais junto ao ortodontista. Permitir novas delegações nas diversas especialidades odontológicas proporcionaria ao cirurgião-dentista uma adequação à realidade atual do mercado de trabalho e regulamentaria alguns procedimentos que já estão sendo delegados à equipe auxiliar.

\section{CONCLUSÕES}

A partir dos dados obtidos e de acordo com a metodologia empregada, é lícito concluir que:

- Diversos procedimentos não permitidos pela legislação estão sendo delegados pelo ortodontista à equipe auxiliar.

- Apenas 25\% dos ortodontistas entrevistados indicou corretamente onde está presente a legislação que regulamenta as atribuições da equipe auxiliar odontológica.

\title{
Utilization of dental assistants in Orthodontics - ethics and legal implications
}

\begin{abstract}
Introduction: the work market has been shown to be saturated with professionals working at large urban centers and, for this reason, productive strategies are indispensable. The delegation of functions to dental assistants is becoming vital and quite common for those that work with Orthodontics. Aim: to evaluate the profile of the orthodontists and the workload delegated by them to the dental assistant team. Methods: a questionnaire was given to all specialists in Orthodontics and Dentofacial Orthopedics registered at the Regional Council of Dentistry of Goiás, with practices in Goiânia and Aparecida de Goiânia. Results and Conclusions: the results demonstrated that orthodontists, in general, take advantage of the work labor of the dental assistants even surpassing the ethical-legal limits.
\end{abstract}

Key words: Orthodontics. Dental assistants. Forensic Dentistry. Ethics. 


\section{REFERÊNCIAS}

1. ABDEL-KADER, K. M. Broken orthodontic trans-palatal archwire stuck to the throat of orthodontic patient: is it strange? Eur $\mathbf{J}$ Orthod, London, v. 30, no. 1, p. 11, 2003

2. BRASIL. Ministério da Saúde. Perfil de competências profissionais do técnico em higiene dental e do auxiliar de consultório dentário. Brasília, DF, 2004. Disponível em: <http://www. saude.gov.br>. Acesso em: 2 maio 2005.

3. CONSELHO FEDERAL DE ODONTOLOGIA. Consolidação das normas para procedimentos nos conselhos de Odontologia: Resolução CFO 063/2005. Rio de Janeiro, 2005. Disponível em: $<$ http://www.cfo.org.br>. Acesso em: 2 maio 2005.

4. CONSELHO FEDERAL DE ODONTOLOGIA. Altera a denominação de atendente de consultório dentário e dá outras providências: Decisão $n^{\circ} 47$. Rio de Janeiro. 2003. Disponível em: <http://www.cfo.org.br>. Acesso em: 2 maio 2005.

5. CONSELHO FEDERAL DE ODONTOLOGIA. Código de Ética Odontológica: Resolução $n^{\circ} 42$. Rio de Janeiro, 2003.

6. CONSELHO FEDERAL DE ODONTOLOGIA (CFO). Dados do CFO. Disponível em: <http://www.cfo.org.br>. Acesso em: 2 maio 2005

7. ELEUTÉRIO, D.; SILVA FILHO, F. P. M. Freqüência da utilização da auxiliar odontológica na atividade clínica do cirurgião-dentista. Rev Assoc Paul Cir Dent, São Paulo, v. 35, n. 2, p. 118-124, 1981.

8. FIGLIOLI, M. D.; PORTO, F. A. Posições de trabalho para o cirurgião-dentista e auxiliar. Parte I. Uso do dique de borracha nos preparos cavitários com visão direta. Odontol Mod, Rio de Janeiro, v. 19, n. 3, p. 14-20, 1992

9. KHARBANDA, O. P.; VARSHNEY, P.; DUTTA, U. Accidental swallowing of a gold cast crown during orthodontic tooth separation. J Clin Pediatr Dent, Birmingham, v. 19, no. 4, p. 289-292, 1995.

10. LEITE, I. N.; PINTO, V. G. Odontologia: um mercado cativo. RGO, Porto Alegre, v. 31, n. 1, p. 41-46, jan./mar. 1983.

11. MARQUART, E. Odontologia ergonômica a quatro mãos. Rio de Janeiro: Quintessência do Brasil, 1980.
12. MILTON, T. M.; HEARING, S. D.; IRELAND, A. J. Ingested foreign bodies associated with orthodontic treatment: report of three cases and review of ingestion/aspiration incident management. Br Dent J, London, v. 190, no. 11, p. 592-596, 2001.

13. PEREIRA, A. C.: MOREIRA, B. H. W. A utilização do auxiliar odontológico para o aumento da produtividade nos serviços públicos. Rev Assoc Paul Cir Dent, São Paulo, v. 46, n. 5, p. 851-854, 1992.

14. SALIBA, T. A. et al. Trabalho odontológico auxiliado em serviços públicos e particulares. RPG Rev Pos-Grad, São Paulo, v. 5 , n. 3, p. 171-176, jul./set. 1998

15. SBRAVATI, R. S.; MENEGHIM, M. C.; PEREIRA, A. C. THD no mercado de trabalho. Uma realidade? ROBRAC, Goiânia. v. 8, n. 25 , ago. 1999.

16. SEEHOLZER, $\mathrm{H}$. et al. A survey of the delegation of orthodontic tasks and the training of chairside support staff in 22 European countries. Eur J Orthod, London, v. 27, no. 3, p. 279-282, Sept. 2000

17. SERRA, M. C. Análise dos sistemas de trabalho adotados por cirurgiões-dentistas brasileiros, em consultórios particulares (montagem do consultório odontológico e utilização de pessoal auxiliar): influência do local e tempo de graduação. 1996. Tese (Doutorado). Faculdade de Odontologia, Universidade Estadual Paulista, Araraquara, 1996

18. SERRA, M. C.; SASSO GARCIA, P. P. Delegação de funções: utilização de pessoal auxiliar na clínica odontológica. Rev ABO Nac, São Paulo, v. 10, n. 2, p. 98-104, abr./maio 2002.

19. TOMASSO, S. Atribuições dos auxiliares odontológicos suas implicações éticas e legais. 2001. Dissertação (Mestrado)Faculdade de Odontologia de Piracicaba. Universidade Estadual de Campinas, Piracicaba, 2001.

20. TURNER, P. J.; PINSON, R. R. Training hygienists for an auxiliary role in orthodontics. Br Dent J, London, v. 175, no. 6, p. 209-213, Sept, 1993.

21. WALSH, M. M. The economic contribution of dental hygienist's activities to dental practice: review of the literature. ASDC $\mathbf{J}$ Dent Child, Chicago, v. 47, no. 4, p. 193-197, 1987.
Endereço para correspondência

Rhonan Ferreira da Silva

Avenida Arumã Qd. 186 Lt. 06, Parque Amazônia

CEP: 74.835-320 - Goiânia/GO

E-mail: rhonanfs@terra.com.br 